\title{
Sex and the Census: Why surveys should not conflate sex and gender identity
}

The UK census authorities have proposed guidance for the 2021 census indicating that the sex question may be answered according to subjective gender identity. This raises issues about the measurement of sex and gender identity which other data collection exercises are also contending with. This paper addresses the questions that have arisen regarding the census, before going on to explain how these questions have emerged more widely. Finally, I address the difficulties of discussing the collection of data on sex in a climate of policy capture and silencing.

Forthcoming in: International Journal of Research Methodology

Professor Alice Sullivan

UCL Institute of Education, Department of Social Science

Alice.sullivan@ucl.ac.uk 


\section{Sex and the Census: Why surveys should not conflate sex and gender identity}

\section{Introduction}

The UK census authorities have proposed guidance for the 2021 census indicating that the sex question may be answered according to subjective gender identity. This raises issues about the measurement of sex and gender identity which other data collection exercises are also contending with. This paper addresses the questions that have arisen regarding the census, before going on to explain how these questions have emerged more widely. Finally, I address the difficulties of discussing the collection of data on sex in a climate of policy capture and silencing.

\section{The 2021 Census}

Proposed online guidance to accompany the sex question in the 2021 census advises respondents that they may answer in terms of their subjective gender identity, rather than their biological or legal sex. The guidance will effectively transform the longstanding sex question into a question about gender identity.

Different versions of the guidance are being used in the census rehearsal for England and Wales, Scotland and Northern Ireland respectively, which could be problematic in itself if differences in the guidance lead to differences in the way the question is answered. Both the England and Wales and Northern Irish versions of the proposed guidance refer to people with intersex conditions (Differences of Sexual Development/DSDs). Concerns have been raised by those supporting families with DSD conditions that these rare congenital conditions should not be conflated with gender identityi.

The census has collected data on sex since its inception in 1801. As a fundamental demographic variable, robust data on the number of male and female citizens is of vital importance to the planning and delivery of public services. Sex is a protected characteristic under the 2010 Equality Act, therefore data on sex is clearly necessary for equalities monitoring. Research and analysis by users of population level data typically presumes the ability to distinguish who is male and female, as a basic explanatory variable.

The sex question was treated as self-explanatory, and issued without guidance until 2011. Guidance issued for the 2011 census advised transsexual and transgender individuals to respond to the sex question based on their self-declared gender identity. This was not subject to consultation, and it is not clear how data quality was affected, but it is likely that few respondents consulted the guidance. The shift to a 'digital-first' census in 2021 means that any proposed guidance will be much more visible and accessible, compared to the 2011 census (which was predominantly paper based, with separate online guidance). It is also likely the number of respondents who might seek to answer the sex question in terms of their gender identity will be higher in 2021. Taken together, these factors introduce the potential for significant discontinuity with the 2011 and previous censuses. 
The 2021 census will include a new, voluntary question on gender identity in 2021 . This could provide valuable data for researchers seeking to understand the prevalence of trans and non-binary identities geographically and across demographic groups, with the proviso that the risk of identifiability may prevent such data being released at the micro level. Due to its scale, the census potentially provides a unique opportunity to provide accurate data on the diverse group described under the 'trans umbrella', as well as the opportunity to give a baseline to track change over time. This has been welcomed, given the current lack of data, and strong interest in understanding the rise of trans identities, particularly among youth. Whereas, among older generations, male-to-female identities were more common than female-to-male, this has been starkly reversed among the younger generation (Littman 2018). The value of the gender identity variable will be maximised if it is combined with accurate data on sex.

The proposed guidance assumes that the number of respondents who self-identify as members of the opposite sex will be small, and that the resulting measurement error will therefore be small compared to other sources of misclassification. However, we currently have no reliable data on the size of the trans population either in the population as a whole or within sub-groups, and crucially, it is impossible to predict how this may change over time. It is unlikely that the trans population will be evenly distributed, for example by age, sex and geography. This means that the effects on data reliability are likely to be greater at the sub-group level. This can have extreme consequences for particular subgroups, e.g. 1 in 50 male prisoners in England and Wales identify as transgender(HM Inspectorate of Prisons 2019). The Tavistock and Portman NHS Trust claims that between $1.2 \%$ and $2.7 \%$ of children and young people are 'gender-diverse'(NIHR 2019).

It is widely understood that survey questions should be clear and specific (Payne 1951). Deliberately muddling together two distinct concepts (sex and gender identity) into one question is therefore a novel approach. This appears to be driven partly by a desire to avoid offending some respondents with a question about their sex, since, if this clashes with their identity, they may not wish to acknowledge this. However, it is hardly unusual for researchers to ask about delicate matters which could potentially offend. Some respondents who are offended by a question may give incorrect information, and some may fail to respond. However, this is not in itself a sufficient justification for guidance which effectively requests a false response.

Of course, all survey designers are mindful of the feelings of respondents, both because of their ethical duty of care, and because they aim to maximise response rates. This sensitivity must extend to all population groups. However, despite assertions that the self-id guidance is motivated partly by a desire to maximise response, testing commissioned by the National Records of Scotland suggests that the overall response rate could in fact be negatively affected by this guidance (ScotCen 2019).

As the UK's most high-profile population survey, changes to the census are likely to influence other data collection exercises. If the decision to reframe the sex question in terms of self-declared gender identity is replicated in other surveys, we are likely to lose data on sex more widely, with detrimental implications for policy-making, research and analysis

There are a number of options open to the census authorities to avoid guidance which conflates sex and gender identity. 1) Remove the guidance. The term sex is self-explanatory, therefore guidance is arguably unnecessary, and no guidance would certainly be better than guidance indicating that the question should be answered incorrectly. 2) Advise respondents to answer in terms of their biological sex. 3) Advise respondents to answer in terms of their legal sex. While option 2 might be preferred in 
terms of the accuracy of sex-based data, in practice, 2 and 3 would be identical for all bar the few respondents in possession of a GRC. There may be issues with requiring GRC holders to disclose their biological sex, so that a biological sex question may have to be optional for this small group. The main risk of option 3 would be to continuity over time, given the possibility that changing legal sex may become more common in the future. However, any of these three options would be preferable to the current proposal.

\section{Sex Matters}

We need accurate data, disaggregated by sex in order to understand differences in the lives of women and men, and in order to tackle sexism. Sex matters from the start of life, as illustrated by international differences in the sex ratio at birth due to son preference (Chao et al. 2019). Sex is a powerful predictor of almost every dimension of social life: education (Stoet et al. 2016), the labour market (Joshi et al. 2019), political attitudes and behaviour (Green and Prosser 2018), religion (Voas 2015), crime (Ministry of Justice 2017), physical health (Koblinsky, Campbell and Harlow 2018), mental health (Ploubidis et al. 2017), cultural tastes and consumption (Sullivan and Brown 2015) - the list goes on. It is difficult to think of an area of life where sex is not an important dimension for analysis. Women have historically been second class citizens when it comes to data (Perez 2019), and a 'male as norm' attitude was still apparent in much quantitative social science as recently as the 1980s. Nevertheless, few quantitative social scientists today would question the central place of sex as an analytic category. So, why are some surveys moving away from asking about or observing sex?

\section{Sex, gender and gender identity}

Increasingly, accurate data collection on sex is being undermined by the conflation of three distinct categories: sex, gender and gender identity.

1. Sex: In humans, sex is a binary biological category. Individuals are classified by reproductive function as male or female. Sex is determined in utero, and is immutable (Kashimada and Koopman 2010; Sobel, Zhu and Imperato-McGinley 2004).

2. Gender: The term 'gender' refers to the stereotypes and social roles that are associated with each sex (Scott 1986). Gender is a social category, rather than an individual one, and refers to how society sees girls and boys and women and men, based on their sex. Gender refers to the hierarchical power structure between men and women (Oakley 1998).

3. Gender identity: The term 'gender identity' refers to some people's sense that they identify psychologically as a member of the male or female sex, particularly when this identity clashes with their biological sex. It refers to how individuals see themselves, rather than how society sees them.

People often use the terms sex and gender as synonyms, perhaps partly due to squeamishness about the word 'sex', but also in order to highlight the point that differences in social and economic outcomes between the sexes are often due to power structures and stereotypes rather than simply biology. This use of sex and gender as interchangeable has become problematic because of changes in the use and understanding of the term 'gender'.

There has been a shift in recent years towards using the term 'gender' to refer to both gender (the social construct) and gender identity (the individual self-perception). The confusion between gender and gender identity is clearly illustrated in ONS materials (Tolland and Evans 2019). Yet, whereas gender is 
rooted in sex, and how others treat us based on our sex, gender identity derives its meaning in opposition to sex. A male may "identify as" a woman, whereas a female simply is a woman. Biological sex and social gender only differ for the very small number of transsexuals who are perceived socially as the opposite sex to their biological sex. This is likely to be a negligible fraction of the group labelled as 'trans' in contemporary usage.

\section{Postmodern fallacies about sex}

Data collection exercises risk being influenced by a set of inter-locking fallacies about sex, which derive from a strand of postmodernist queer theory, which can be labelled 'genderism'. The key fallacies are as follows:

1. There are more than two sexes, and/or sex is a spectrum.

2. People with intersex conditions are a 'third sex' and/or intersex conditions are a form of gender identity.

3. Sex is a (western) social construct which is arbitrarily assigned at birth.

4. Non-binary individuals are neither male nor female.

5. It is offensive to acknowledge the existence of biological sex.

The claim that there are more than two sexes originates with the influential queer theorist Anne FaustoSterling, who first posited the existence of five sexes, sliding into the claim that sex is a continuous variable "Indeed, I would argue further that sex is a vast, infinitely malleable continuum that defies the constraints of even five categories." (Fausto-Sterling 1993). Fausto-Sterling later dialled back from such bold claims, in favour of the more nebulous notion that "...sex and gender are best conceptualized as points in a multidimensional space". (Fausto-Sterling 2000). As absurd as it may appear, the claim that sex is not binary appears to be gaining credence through sheer repetition (Wright and Hilton 2020). For example, a recent paper published in the journal Significance claims that "There is a growing recognition in scientific, social and political spheres that gender and sex vary across a continuum." (Alba, Wong and Bråten 2019). If sex really was a spectrum, then presumably we would need to measure it according to some kind of scale, yet so far, no such scale has been proposed.

Fausto-Sterling's claim that sex is not binary relies on the existence of people with intersex conditions, also known as Differences of Sex Development (DSDs). These conditions are estimated to apply to $0.018 \%$ of births (Sax 2002). It is clearly a fallacy to suggest that the existence of a small minority of anomalous cases invalidates the existence or usefulness of a categorical variable. From the point of view of social statistics, it is strange indeed that such a tiny element of noise or error should be seen as problematic. Think of any other category used in social science - social class, educational level, ethnic group - and it is obvious that each of these concepts is far murkier and more open to measurement ambiguity and error than sex. Sex is arguably the cleanest variable in our arsenal.

People with DSD conditions are not a 'third sex' (or a fourth or fifth sex for that matter) and their conditions have nothing to do with trans identities. But the genderist ideology uses intersex conditions to argue that binary sex is not a biological reality, but a western social construct. Fausto-Sterling claims that "Western culture is deeply committed to the idea that there are only two sexes" (Fausto-Sterling 1993). This sows the seed for the startling and frankly, racist trope that 'non-western' people had binary sex imposed on them by imperialists - how genderist queer theorists imagine these innocents managed 
to reproduce before the advent of imperialism is unclear. In this paradigm, sex is not determined in utero and noted at birth, but arbitrarily "assigned at birth". Birth certificates do not simply note sex, they actually create the sexed body (Holzer 2019). The use of DSD conditions in the service of an ideological cause which is unrelated to these conditions has caused offence and upset to many DSD families and campaigners (Dreger 2016).

While trans people identify as the opposite sex, 'non-binary' people claim an identify which is outside the gender binary. If this implies some level of discomfort with the stereotypes associated with both sexes, then clearly this may apply to vast swathes of people, perhaps to everyone. Yet, clearly, people who describe themselves as non-binary come in two sexes, male and female, the same as everyone else.

The tendency to shy away from asking which sex a survey respondent belongs to appears to be based on the view that it is offensive to ask people who identify as trans or non-binary about their sex, often phrased hyperbolically as the claim that acknowledging sex erases people's identities or denies their existence. Yet sex and gender identity are two distinct concepts. Indeed, trans identity derives it's meaning from sex, since being trans implies incongruence between sex and identity.

The fallacies listed above are reflected, whether wittingly or not, in survey items which ask the respondent's gender instead of their sex, which give additional response categories alongside male/female when asking for the respondent's sex (e.g. are you male/female/trans/nonbinary/intersex), or which ask whether the respondent's 'gender' is different from their 'sex assigned at birth'.

\section{The political agenda, policy capture and silencing}

It is impossible to understand the proposed change to the meaning of the sex question in the census without reference to a broader political project aimed at replacing sex with gender identity in law, language and data-collection.

Much of the general public within the UK only started to become aware of gender identity as a political project as a result of proposed changes to the 2004 Gender Recognition Act (GRA) by the Scottish and UK Governments in 2017 and 2018 respectively. The GRA allows transsexual individuals with a medical diagnosis of gender dysphoria to change their legal sex if certain conditions are met. Since the Act came into force around 5,000 people have acquired a Gender Recognition Certificate (GRC) i. Both Governments consulted on proposals to remove all medical gate-keeping and replace this with a statutory self-declaration process, thereby making GRCs accessible to a much larger number of people who may identify as trans without experiencing gender dysphoria, and without the need to demonstrate that they have been through any medical or social transition. The current UK Government now appears to have dropped its plans for reform, while at the time of writing, the Scottish Government is consulting a draft Bill aimed at introducing statutory self-declaration. Yet the principles behind the proposed changes have already been accepted by many public bodies. Examples in practice include police forces recording crimes committed by men as though they were committed by women at the request of the perpetrator (Burden 2019), organisational pay-gap data being collected according to gender identity rather than sex (ACAS 2019), and the replacement of actual sex with the desired sex on medical records at patients' request (MBM Policy Analysis 2020b). 
Gender identity lobbyists have campaigned for many years to remove sex as a protected characteristic in law (WPUK 2020). Much of this campaigning has been done quietly, behind the scenes, within social and political institutions and organisations, without public debate, due process or democratic scrutiny, a process termed 'policy capture' (Murray and Hunter Blackburn 2019). Murray and Hunter Blackburn outline the way that the census authorities have been lobbied by and have consulted with genderist organisations since at least 2008, whereas groups representing women's interests have not been consulted. Neither has there been specific discussion of the move away from collecting clear data on sex with academic researchers or public bodies which use this data. "This change is only happening because of intense lobbying by groups which promote the view that sex should be treated as irrelevant where it contradicts self-declared gender identity." (MBM Policy Analysis 2020a)(p.2).

The question of sex and gender identity is marked by exceptional intolerance of dissent by genderist extremists, and a remarkably successful campaign to shut down debate. Academics face campaigns of vexatious complaints, no-platforming, and even threats of violence simply for asserting the reality and social salience of sex, especially when they do so from a feminist perspective (Sullivan and Suissa 2019). This has a wider chilling effect, meaning that normal open and rigorous discourse is effectively suspended. Critical voices are no longer heard, and so a false 'consensus' emerges.

\section{Case study}

A letter to the census authorities asking them to reconsider their approach to the sex question was signed by 80 quantitative social scientists, including ten Fellows of the British Academy, and several leaders of major social surveys (Griffiths 2019). Yet, such is the climate of fear on this issue that some colleagues did not feel able to sign the public version of the letter, or to sign at all. One colleague who felt constrained by job insecurity explained that they could not take the potential career hit: "So with a very heavy heart I have chosen to swallow my integrity on this particular issue and keep my head down. I don't like doing this, and I don't like how it feels. I don't like the implications of my inaction for social justice in general or gender issues in particular. ${ }^{\prime \prime i i i ~}$

This colleague's fears were not misplaced. The CEO of a major UK research organisation which is working closely with ONS on the census wrote to all staff instructing them not to sign the letter to the census authorities, claiming that this could risk damaging the perceived independence of the organisation, and stating that "We know that staff endorsing this letter may cause upset and offence to some of our LGBT+

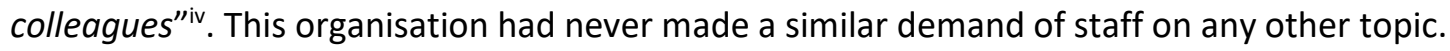

I had been invited to speak at a research methods seminar on sex and gender issues in data collection at this organisation, on a panel including representatives from ONS. The event was cancelled. When I challenged the organisation on the reasons for this, I was told that including me was 'too risky', and that either the chair or one of the other speakers had threatened to pull out if I was given a platform (threatening to pull out of an event if another speaker is included is a standard no-platforming technique). A staff group had also applied pressure. An internal email stated "The LGBT+ group feel that including her as a panellist could be seen as [organisation name] endorsing anti-trans views, risking reputational damage and, perhaps more importantly, risking harm to staff and audience members. They have suggested that she should not take part, or that the event be cancelled." No evidence was provided for these supposed "anti-trans views" or of any risk of actual harm. However, it is now commonplace for people who believe in the reality and importance of sex as a category to be accused of transphobia, simply on the basis of this belief, regardless of their complete commitment to upholding 
the human rights of trans people. By no-platforming such people, organisations are refusing to engage with evidence-based positions which are widely held within the relevant community of experts. This cannot be healthy, particularly in a context where policy is being formed.

This example is not atypical. Academics, research organisations and policymakers need to be alert to this climate of fear and silencing in order to counter it. This makes it even more important than it would be on other topics that experts are actively consulted. Rigorously seeking out genuine expertise protects against policy capture. Troublingly, the census authorities appear to have treated submissions from university staff with no relevant disciplinary expertise, but a clear ideological agenda, with at least equal weight to the views of population data users (MBM Policy Analysis 2020c). As online activism among university staff and students becomes increasingly prevalent, it is important that the organisations being lobbied are able to distinguish between self-identified experts and genuine ones.

\section{Conclusions}

Sex and gender identity are entirely distinct concepts. The census, and surveys in general, need to avoid conflating them.

Without accurate data on sex, we lose the ability to understand differences and to design evidencebased policies tackling problems facing girls and boys, women and men. We also lose the ability to gain an accurate understanding of issues facing trans people of both sexes.

A culture of silencing and policy capture by gender identity lobbyists uniquely affects this aspect of data collection, shutting down critical discussion, and allowing normal measurement considerations to be brushed aside.

The postmodernist project is explicitly anti-scientific (Sokal and Bricmont 1998). It is vital that those of us who work with social statistics understand the origins of the attempt to dismantle sex as a category in postmodernist queer theory. For queer theorists, dismantling categories is a political project. Social scientists who are interested in measuring social phenomena that are 'out there' in the real world should understand that the postmodernists who used to denigrate all quantitative research are now coming for our questionnaires. Resisting postmodernism matters for everyone who believes that the distinction between fact and fiction matters for research and policy. 


\section{Bibliography}

ACAS. 2019. Managing gender pay reporting. https://archive.acas.org.uk/media/4764/Managinggender-pay-reporting/pdf/Managing gender pay reporting 07.02.19.pdf: Government Equalities Office.

Alba, Sandra, Franz Wong, and Yngve Bråten. 2019. "Gender matters in household surveys." Significance 16(6):38-41.

Burden, E. 2019. "Letting criminals self-identify gender 'putting women at risk'." The Times https://www.thetimes.co.uk/article/letting-criminals-self-identify-gender-putting-women-atrisk-8560wzkqt (14th March 2019).

Chao, Fengqing, Patrick Gerland, Alex R Cook, and Leontine Alkema. 2019. "Systematic assessment of the sex ratio at birth for all countries and estimation of national imbalances and regional reference levels." Proceedings of the National Academy of Sciences 116(19):9303-11.

Dreger, Alice. 2016. Galileo's middle finger: Heretics, activists, and one scholar's search for justice: Penguin Books.

Fausto-Sterling, Anne. 1993. "The five sexes: Why male and female are not enough." SCIENCES-NEW YORK-33:20-20.

-. 2000. "The five sexes, revisited." The sciences:17-23.

Green, Jane, and Chris Prosser. 2018. "Women, men, and the 2017 general election. By Jane Green and Chris Prosser." https://www.britishelectionstudy.com/bes-findings/women-men-and-the-2017general-election-by-jane-green-and-chris-prosser/\#.XI5bej 7Q0M: British Election Study.

Griffiths, Sian. 2019. "Sex question catapults census into trans war." in The Sunday Times. https://www.thetimes.co.uk/article/sex-question-catapults-census-into-trans-war-vq29nfvsg.

HM Inspectorate of Prisons. 2019. HM Chief Inspector of Prisons for England and Wales: Annual Report 2018-19.

https://assets.publishing.service.gov.uk/government/uploads/system/uploads/attachment dat a/file/814689/hmip-annual-report-2018-19.pdf: House of Commons.

Holzer, Lena. 2019. "Sexually Dimorphic Bodies: A Production of Birth Certificates." Australian Feminist Law Journal 45(1):91-110.

Joshi, Heather, Alex Bryson, David Wilkinson, and Kelly Ward. 2019. "The gender gap in wages over the life course: evidence from a British cohort born in 1958." IZA DP No. 12725.

Kashimada, Kenichi, and Peter Koopman. 2010. "Sry: the master switch in mammalian sex determination." Development 137(23):3921-30.

Koblinsky, Marjorie A, Oona MR Campbell, and Siobán D Harlow. 2018. "Mother and more: a broader perspective on women's health." Pp. 33-62 in The Health Of Women: Routledge.

Littman, Lisa. 2018. "Rapid-onset gender dysphoria in adolescents and young adults: A study of parental reports." PloS one 13(8):e0202330-e30.

MBM Policy Analysis. 2020a. "MBM view on proposals for the sex question in the UK 2021 census." https://murrayblackburnmackenzie.org/2020/02/07/mbm-view-on-proposals-for-the-sexquestion-in-the-uk-2021-census/.

-. 2020b. Recording sex on medical records: a case study of NHS Scotland. https://murrayblackburnmackenzie.org/2020/01/12/recording-sex-on-medical-records-a-casestudy-of-nhs-scotland/.

-. 2020c. "A tale of two letters: whose views count?". https://murrayblackburnmackenzie.org/2020/02/24/a-tale-of-two-letters-whose-views-count/.

Ministry of Justice. 2017. "Statistics on Women and the Criminal 
Justice System 2017."

https://assets.publishing.service.gov.uk/government/uploads/system/uploads/attachment dat a/file/759770/women-criminal-justice-system-2017..pdf.

Murray, Kath, and Lucy Hunter Blackburn. 2019. "Losing sight of women's rights: the unregulated introduction of gender self-identification as a case study of policy capture in Scotland." Scottish Affairs 28(3):262-89.

NIHR. 2019. "Outcomes and Predictors of Outcome for Children and Young People Referred to UK Gender Identity Development Services: A longitudinal Investigation, award 17/51/19." in NIHR Funding and Awards. https://fundingawards.nihr.ac.uk/award/17/51/19: National Institute for Health Research.

Oakley, Ann. 1998. "Science, gender, and women's liberation: An argument against postmodernism." Pp. 133-46 in Women's Studies International Forum: Elsevier.

Payne, Stanley Le Baron. 1951. The Art of Asking Questions: . New Jersey: Princeton University Press.

Perez, Caroline Criado. 2019. Invisible Women: Exposing data bias in a world designed for men: Random House.

Ploubidis, GB, A Sullivan, M Brown, and A Goodman. 2017. "Psychological distress in mid-life: evidence from the 1958 and 1970 British birth cohorts." Psychological Medicine 47(2):291-303.

Sax, Leonard. 2002. "How common is Intersex? A response to Anne Fausto-Sterling." Journal of sex research 39(3):174-78.

ScotCen. 2019. Testing guidance for the sex question: Scotland's Census 2021. https://www.scotlandscensus.gov.uk/documents/ScotCen\%20\%20Testing\%20guidance\%20for\%20the\%20sex\%20question\%20-\%20December\%202019.pdf: National Records of Scotland.

Scott, Joan W. 1986. "Gender: a useful category of historical analysis." The American historical review 91(5):1053-75.

Sobel, Vivian, Yuan-Shan Zhu, and Julianne Imperato-McGinley. 2004. "Fetal hormones and sexual differentiation." Obstetrics and Gynecology Clinics 31(4):837-56.

Sokal, A., and J. Bricmont. 1998. Intellectual Impostures: Profile Books.

Stoet, Gijsbert, Drew H Bailey, Alex M Moore, and David C Geary. 2016. "Countries with higher levels of gender equality show larger national sex differences in mathematics anxiety and relatively lower parental mathematics valuation for girls." PloS one 11(4).

Sullivan, Alice, and Matthew Brown. 2015. "Vocabulary from adolescence to middle age." Longitudinal and Life Course Studies 6(2):173-89.

Sullivan, Alice, and Judith Suissa. 2019. "The gender wars, academic freedom and education." https://www.bera.ac.uk/blog/the-gender-wars-academic-freedom-and-education: British Educational Research Association (BERA).

Tolland, L., and J. Evans. 2019. "What is the difference between sex and gender? Exploring the difference between sex and gender, looking at concepts that are important to the Sustainable Development Goals." https://www.ons.gov.uk/economy/environmentalaccounts/articles/whatisthedifferencebetwee nsexandgender/2019-02-21: Office for National Statistics.

Voas, David. 2015. "Religious involvement over the life course: problems of measurement and classification." Longitudinal and Life Course Studies 6(2):212-27.

WPUK. 2020. "Evidence of calls to remove single sex exemptions from Equality Act." in Woman's Place UK. https://womansplaceuk.org/references-to-removal-of-single-sex-exemptions/.

Wright, Colin M., and Emma N. Hilton. 2020. "The dangerous denial of sex." Wall Street Journal February 14th 2020. 
'Evidence submitted to the Scottish Parliament's Culture, Tourism, Europe and External Affairs (CTEEA) Committee during the passage of the Census (Amendment) (Scotland) Act 2019 from charity DSD Families.

ii https://www.gov.uk/government/consultations/reform-of-the-gender-recognition-act-2004

iii Private correspondence to the author.

iv Email retrieved via Data Access Request.

$\checkmark$ Email retrieved via Data Access Request. 